\title{
Peranan Rumah Sakit Jiwa Mahoni Dalam Mengembalikan Keberfungsian Sosial Eks Orang Dengan Gangguan Jiwa
}

\section{The Role of Mahogany Mental Hospital in Restoring the Social Functions of Ex People with Mental Disorders}

\author{
Yuli Ekasari, Efendi Agus* \\ Program Studi di Kesejahteraan Sosial, Fakultas Ilmu Sosial dan Ilmu Politik, \\ Universitas Muhammadiyah Sumatera Utara, Indonesia \\ *E-mail: efendiagus@umsu.ac.id
}

\begin{abstract}
Abstrak
Penelitian ini membahas tentang peranan rumah sakit jiwa dalam mengembalikan keberfungsian sosial eks orang dengan penyakit jiwa. Teori yang digunakan dalam penelitian ini adalah teori peran dan teori keberfungsian sosial. Penelitian ini untuk mengetahui tentang bagaimana peranan Rumah Sakit Jiwa Mahoni dalam mengembalikan keberfungsian sosial eks orang dengan gangguan jiwa didalam keluarga. Penelitian ini menggunaan metode deskriptif kualitatif. Informan dalam penelitian ini sebanyak 8 orang yang terdiri 1 orang pimpinan rumah sakit, 3 orang team medis dan 4 orang eks orang dengan gangguan jiwa. Teknik pengumpulan data yang digunakan yakni wawancara dan dokumentasi. Teknis pengolahan data dengan reduksi data, penyajian data dan penarikan kesimpulan. Hasil penelitian menunjukkan bahwa peranan Rumah Sakit Jiwa Mahoni dalam mengembalikan keberfungsian sosial eks orang dengan gangguan jiwa sudah mengarah pada kesembuhan. Hal ini dapat dilihat dari eks orang dengan gangguan jiwa setelah melakukan perawatan dan penyembuhan mengalami banyak perubahan mental yang lebih positif. mereka memiliki keberfungsian sosial untuk kembali ke keluarganya dan menjalani kehidupan sesuai harapannya bersama keluarganya.
\end{abstract}

Kata Kunci: Peranan, keberfungsian sosial, Eks Orang Dengan Gangguan Jiwa

\begin{abstract}
This study discusses the role of mental hospitals in restoring the social functioning of ex-people with mental illness. Theories used in this research are role theory and social functioning theory. This research is to find out about the role of Mahoni Mental Hospital in restoring the social functioning of ex-people with mental disorders in the family. This research uses descriptive qualitative method. The informants in this study were 8 people consisting of 1 hospital leader, 3 medical teams and 4 ex-people with mental disorders. Data collection techniques used are interviews and documentation. Data processing techniques with data reduction, data presentation and conclusion drawing. The results showed that the role of the Mahoni Mental Hospital in restoring the social functioning of ex-people with mental disorders had led to healing. This can be seen from former people with mental disorders after treatment and healing experience many more positive mental changes. they have a social function to return to their families and live their lives as they wish with their families.
\end{abstract}

Keywords: Role, social functioning, Ex People with Mental Disorders

Cara citasi : Ekasari, Yuli. Agus, Efendi. (2020). Peranan Rumah Sakit Jiwa Mahoni Dalam Mengembalikan Keberfungsian Sosial Eks Orang Dengan Gangguan Jiwa. Jurnal Intervensi Sosial dan Pembangunan (JISP) Vol 1 No 1 Maret 2020, 44-57. 


\section{PENDAHULUAN}

Kesehatan jiwa menjadi salah satu permasalahan yang signifikan didunia, termasuk di negara Indonesia. Menurut data Organisasi kesehatan Dunia (WHO 2016) terdapat 35 juta orang mengalami gangguan mental. Negara Indonesia memiliki jumlah penduduk sekitar 268.369.114 (Sensus 2019). Upaya penanganan terhadap orang dengan gangguan kejiwaan di Indonesia memiliki banyak keterbatasan baik rumah sakit jiwa dan tenaga medis khususnya di dunia kesehatan jiwa masih sangat kurang.

Gangguan jiwa disebabkan oleh faktor sosial, yakni Penyandang Masalah Kesejahteraan Sosial (PMKS) merupakan individu, keluarga atau kelompok masyarakat yang karena suatu hambatan atau kesulitan atau gangguan, tidak dapat melaksanakan fungsi sosialnya sehingga tidak dapat terpenuhi kebutuhan hidupnya secara memadai dan wajar. Orang dengan gangguan jiwa merupakan salah satu dari penyandang disabilitas, sebagian istilah disebut sebagai orang gila. Gangguan mental (mental disorder) menurut perspektif Diagnostic and Statistical Manual of Mental Disorder (DSM) adanya gangguan klinis yang bermakna berupa sindrom atau pola perilaku dan psikologi, gejala klinis tersebut menimbulkan penderitaan antara lain dapat berupa rasa nyeri, tidak nyaman, tidak tenteram dan disfungsi organ tubuh. Disamping itu, juga menimbulkan gejala disabilitas dalam aktifitas kehidupan seharihari yang biasa dan diperlukan untuk perawatan diri dan kelangsungan hidup.

Untuk memajukan, melindungi, menjamin kesamaan hak dan kebebasan yang mendasar semua penyandang disabilitas, Maka salah satu kewajiban Negara untuk menjamin dan memajukan pemenuhan hak penyandang disabilitas dituangkan didalam Undang-Undang Nomor 19 tahun 2011 tentang konvensi mengenai hak-hak Penyandang Disabilitas termasuk didalamnya orang dengan gangguan jiwa.

Menurut UU No.18 Tahun 2014 tentang Kesehatan Jiwa (UUKJ) pada Pasal 1 ayat 3 menyatakan bahwa Orang Dengan Gangguan Jiwa (ODGJ) adalah orang yang mengalami gangguan dalam pikiran, perilaku, dan perasaan yang termanifestasi dalam bentuk sekumpulan gejala dan/atau perubahan perilaku yang bermakna, serta dapat menimbulkan penderitaan dan hambatan dalam menjalankan fungsi orang sebagai manusia" maka dari itu orang dengan gangguan jiwa membutuhkan upaya penyembuhan yang khusus dan terstruktur agar dapat kembali normal sebagaimana mestinya dalam menjalankan kehidupan. Didalam Undang-Undang Nomor 11 Tahun 2019 pasal 6, menyebutkan bahwa rehabilitasi sosial merupakan salah satu bentuk intervensi sosial 
Ekasari, Yuli. Agus, Efendi. Peranan Rumah Sakit Jiwa Mahoni Dalam Mengembalikan Keberfungsian Sosial Eks Orang Dengan Gangguan Jiwa

untuk menyelenggarakan kesejahteraan sosial disamping jaminan sosial, pemberdayaan sosial dan perlindungan sosial.

Kebutuhan kita akan interaksi sosial merupakan kebutuhan dasar yang melekat pada eksistensi kita sebagai manusia, dan tentu tidak interaksi biasa tapi interaksi sosial yang berkualitas yang dibangun atas dasar kasih sayang, ketulusan dan harmoni. Untuk mencapai interaksi sosial yang harmonis dan didasari dengan kasih sayang bukanlah sesuatu yang mudah. Ilmu psikologi yang secara khusus mempelajari proses mental dan perilaku manusia dalam seting sosial disebut psikologi sosial (Rahman, 2013). Keberfungsian sosial sangat berarti bagi individu, keluarga, kelompok, dan masyarakat yang secara normal dapat memenuhi kebutuhannya dalam berinteraksi dengan lingkungan (Huda, 2009).

Untuk meminimalisir permasalahan kesejahteraan sosial khususnya pada penyandang disabilitas yaitu orang dengan gangguan jiwa sangatlah dibutuhkan peranan sebuah instansi yaitu Rumah Sakit Jiwa. Rumah Sakit Jiwa Mahoni melakukan perannya sebagai rumah sakit jiwa tingkat provinsi yang ada di kota Medan. Rumah Sakit Jiwa Mahoni cukup memiliki peran penting, Peran penting tersebut bagi pasien gangguan penyakit jiwa yang ada di Rumah Sakit Jiwa Mahoni adalah program peningkatan pengetahuan dan keterampilan, kegiatan ceramah bagi beragama islam, siraman rohani bagi beragama kristen, games dan olahraga tetapi, program yang mendapat dukungan terbanyak adalah program seperti kegiatan kursus rutin seperti melukis dan mewarnai.

Rumah Sakit Jiwa Mahoni Medan mengemban tugas membantu pemerintah dalam bidang kesehatan, terutama di bidang kejiwaaan seseorang. Rumah Sakit Jiwa Mahoni mempunyai tugas untuk melaksanakan upaya kesehatan secara berdaya guna dan berhasil guna dengan mengutamakan penyembuhan dan pemulihan terhadap pasien, terutama kejiwaan pasien, untuk menjalankan tugasnya dalam membantu masyarakat dibidang kesehatan, terutama kesehatan jiwa maka Rumah Sakit Jiwa Mahoni Medan didukung oleh sumber daya manusia yang baik dan benar.

Orang dengan gangguan jiwa menjalani proses penyembuhan dengan melaksanakan program penyembuhan kombinasi baik medis dan psikologis serta teratur konsumsi obat-obatan, yang tidak kalah penting adalah dukungan psikososial sebab Mereka merasa mendapatkan dukungan untuk sembuh. Rumah Sakit Jiwa Mahoni Medan merawat orang dengan gangguan jiwa hingga Eks orang dengan gangguan jiwa tersebut 
diharapkan dapat berkumpul dengan keluarganya kembali dan melakukan fungsi sosialnya dengan baik.

Eks gangguan jiwa adalah seseorang yang pernah mengalami gangguan pada fungsi kejiwaan, seperti proses berfikir, emosi, kemauan, dan perilaku psikomotorik. Penderita gangguan jiwa sering tidak menyadari apa yang sebenarnya sedang terjadi pada dirinya, ia gelisah, cemas, tidak bersemangat, terkadang takut, ragu-ragu, tidak percaya diri, tetapi ia sendiri tidak tahu persis apa sebenarnya yang menyebabkan keadaan tersebut. Secara definitif eks gangguan jiwa adalah orang yang pernah mengalami gangguan pada fungsi kejiwaan, seperti proses berfikir, emosi, kemauan dan perilaku psikomotorik (Suliswati, 2005).

Berdasarkan dari permasalahan tersebut, maka peneliti tertarik untuk melakukan penelitian dengan judul "peranan rumah sakit jiwa mahoni dalam mengembalikan keberfungsian sosial eks orang dengan gangguan jiwa didalamkeluarga”.

\section{METODE PENELITIAN}

Jenis penelitian digunakan dalam penelitian ini adalah metode penelitian deskriptif dengan pendekatan kualitatif, data yang disampaikan dalam bentuk verbal, menekankan pada persoalan kontekstual tidak terikat dengan perhitungan angkaangka, ukuran yang bersifat empiris. Menurut Moleong (2006) penelitian kualitatif merupakan penelitian yang memanfaatkan wawancara terbuka untuk menalaah dan memahami sikap, pandangan, perilaku individu dan kelompok orang. Pendekatan ini diarahkan pada latar belakang individu secara holistic menggunakan metode deskriptif. Melalui pendekatan ini dapat memberikan gambaran penelitian ini adalah menjelaskan tentang bagaimana peranan rumah sakit jiwa mahoni dalam mengembalikan keberfungsian sosial eks orang dengan gangguan jiwa didalam keluarga.

Teknik pengumpulan data penelitian utama yang digunakan adalah wawancara mendalam, observasi partisipasi, dan dokumentasi. Wawancara yang dilakukan penulis dalam penelitian dimaksudkan untuk mengetahui pandangan, kejadian, kegiatan, pendapat, perasaan dari narasumber (subjek matter expert). Observasi yang dilakukan dalam penelitian ini terhadap objek yang diteliti. Studi dokumentasi diperlukan terutama untuk memperkaya landasan-landasan teoritis dan mempertajam analisis penelitian yang berkaitan dengan peranan rumah sakit jiwa mahoni dalam mengembalikan keberfungsian sosial eks orang dengan gangguan jiwa didalam keluarga. 
Ekasari, Yuli. Agus, Efendi. Peranan Rumah Sakit Jiwa Mahoni Dalam Mengembalikan Keberfungsian Sosial Eks Orang Dengan Gangguan Jiwa

Sesuai dengan judul penelitian ini yaitu Peranan rumah sakit jiwa mahoni dalam mengembalikan keberfungsian sosial eks orang dengan gangguan jiwa didalam keluarga, maka Penelitian ini dilaksanakan di Rumah Sakit Jiwa Mahoni. Alasan peneliti memilih Rumah Sakit Jiwa Mahoni sebagai tempat penelitian karena merupakan lembaga/instansi yang memiliki peran dalam menyembuhkan dan memulihkan penderita gangguan jiwa juga sebagai rumah sakit jiwa tingkat provinsi yang ada di kota Medan.

\section{HASIL DAN PEMBAHASAN}

\section{Peranan Rumah Sakit Jiwa Mahoni Mengembalikan Keberfungsian Sosial Eks Orang Dengan Gangguan Jiwa}

Rumah Sakit Jiwa Mahoni Medan mengemban tugas membantu pemerintah dalam bidang kesehatan, terutama di bidang kejiwaaan seseorang. Rumah Sakit Jiwa Mahoni mempunyai tugas untuk melaksanakan upaya kesehatan secara berdaya guna dan berhasil guna dengan mengutamakan penyembuhan dan pemulihan terhadap pasien, terutama kejiwaan pasien. Untuk menjalankan tugasnya dalam membantu masyarakat dibidang kesehatan, terutama kesehatan jiwa maka Rumah Sakit Jiwa Mahoni didukung oleh sumber daya manusia yang baik dan benar.

Menurut Rukminto (2013:98) pembagian peran dalam bidang kesehatan jiwa ini sebenernya erat kaitannya dengan pandangan manusia sebagai makhluk bio-psikososial. Sehingga dalam intervensi terhadap penderitaa gangguan jiwa, intervensi dilakukan terhadap elemen biologis, psikis dan sosial yang terkait dengan kelhidupan klien. Maka peran konselor (caseworker) untuk meyakinkan kliennya bahwa perubahan yang ia capai adalah perubahan yang bermakna, dan ia diharapkan untuk tetap dapat melanjutkan treatment tersebut. Dalam proses terapi yang ia jalani, dirinyalah yang dapat menentukan bagaimana hasil yang akan di capai. Fungsi caseworker, antara lain adalah: a). Membantu klien agar dapat mengembangkan diri, b). Membantu klien agar dapat memilih pemecahan masalah yang terbaik untuk diri klien itu sendiri, dan c). Membantu membantu membangkitkan motivasi klien untuk bergerak kearah yang lebih baik dan memonitor perkembangan klien.

Gangguan atau penyakit mental adalah sesuatu yang menghalangi seseorang hidup sehat seperti yang diinginkannya, baik oleh individu itu sendiri maupun orang lain. Gangguan jiwa sering disebut dengan tidak sehat mental. Sehat mental atau kesehatan 
jiwa adalah suatu kondisi yang memungkinkan perkembangan fisik, intelektual dan emosional yang optimal dari seseorang dan perkembangannya itu berjalan selaras dengan orang lain pada umumnya (Yustinus, 2006).

Gangguan Jiwa adalah orang yang mengalami gangguan dalam pikiran, perilaku, dan perasaan yang termanifestasi dalm bentuk sekumpulan gejala dan/atau perubahan perilaku yang bermakna serta dapat menimbulkan penderitaan dan hambatan dalam menjalankan fungsi orang sebagai manusia (UU RI No.18, 2014).

Penelitian ini akan dilakukan terhadap 1 pimpinan rumah sakit jiwa mahoni dan 3 team medis yakni perawat, 4 eks orang dengan gangguaan jiwa dikarenakan data yang didapatkan sudah valid . sesuai dengan kategorisasi yang sudah diuraikan, maka akan di bahas mengenai gambaran tentang peranan rumah sakit jiwa mahoni dalam mengembalikan keberfungsian sosial eks orang dengan gangguan jiwa didalam keluarga yang meliputi program penyembuhan dan proses penyembuhan.

\section{Aspek Program Penyembuhan}

Hasil penelitian terhadap 4 eks orang dengan gangguan jiwa menunjukkan bahwa rumah sakit jiwa memberikan program penyembuhan sangat berperan penting dalam membantu mereka pulih. Seperti bapak Hamonangan Sagala yang berusia 57 tahun dan bekerja sebagai wiraswasta. dia dirawat selama 1 tahun 6 bulan di Rumah Sakit Jiwa mahoni karena sikap emosionalnya yang berlebihan.

"kondisi bapak alhamdulillah sekarang udah cukup baik setelah di rawat di

Rumah Sakit Jiwa mahoni. Bapak juga udah kembali kerja lagi. setiap hari bapak minum obat resep dokter biar berkurang emosional bapak. Pokoknya 1 bulan 1 kali ada pergi kontrol periksa“ (Hasil wawancara yang diperoleh dari Bapak Hamonangan Sagala tanggal 26 Juli 2019).

Beda halnya dengan seorang mahasiswa yang pernah di rawat di Rumah Sakit Jiwa Mahoni selama 11 hari bernama Alni Rafiqi Sagala, anak laki-laki berusia 24 tahun. Memotivasi dirinya untuk dapat segera pulih setelah menjalani rawat inap di rumah sakit jiwa mahoni karena ilusi dan berhalusinasi. Dengan menjalani perawatan harapannya dapat kembali menjalankan aktifitasnya sebagai mahasiswa.

"Aku minum obatnya 2 kali sehari kalau habis langsung beli lagi resep nya, kondisi sekarang udah lebih baiklah dari kemarin. Ini udah bisa masuk kelas 
Ekasari, Yuli. Agus, Efendi. Peranan Rumah Sakit Jiwa Mahoni Dalam Mengembalikan Keberfungsian Sosial Eks Orang Dengan Gangguan Jiwa

lagi. Pengen cepat lulus biar bisa kerja mbak" (Hasil wawancara yang diperoleh dari Alni Rafiqi Sagala tanggal 26 Juli 2019).

Sedangkan bapak Armasnyah yang berusia 33 tahun yang berasal dari sumatera barat pernah menjalani perawatan di Rumah Sakit Jiwa Mahoni selama 3 minggu karena emosional dan kadang memiliki sifat bingung atau linglung.

"Setelah dirawat disana Alhamdulillah aku udah semakin membaik, ya udah gak bingung lagi gak emosian lagi. Sekarang ini aku masih minum obat 2 kali sehari tiap hari sama datang ke rumah sakit $2 \mathrm{x}$ seminggu disuruh dokter. Aku ada niatan mau buka usaha di kampungku, doai aku sembuh ya”. (Hasil wawancara yang diperoleh dari Bapak Armasnyah tanggal 26 Juli 2019).

Berikutnya Bapak Edi Surya berusia 39 tahun yang bermata pencaharian sebagai seorang seorang yang bekerja diladang. Pak edi salah satu pasien yang pernah dirawat di Rumah Sakit Jiwa Mahoni selama 2 bulan karena kondisi pak edi yang selalu marahmarah.

"Senang rasanya bisa berobat jadi bisa kerja diladang lagi, udah kurang malah jarang marah-marah lagi aku dirumah. Aku minum obat terus dari dokter tapi aku gak jarang pernah kontrol”. (Hasil wawancara yang diperoleh dari Bapak Edi Surya tanggal 26 Juli 2019).

Mengenai program penyembuhan yang dilaksanakan di Rumah Sakit Jiwa Mahoni yakni rawat inap dan rawat jalan saja. Seperti wawancara saya dengan pimpinan Rumah Sakit Jiwa Mahoni Medan Ibu dr. Purnama Sari Dalimunthe, beliau menjabat sebagai pimpinan baru sekitar 7 bulan.

"Rumah Sakit Jiwa Mahoni memiliki peranan dalam menangani pasien gangguan jiwa serta membantu mengurangi tingkat penderita gangguan jiwa, kami disini memiliki tenaga medis yang memiliki sumber daya manusia yang baik yang dapat menjalanankan program penyembuhan pada penderita gangguan jiwa. Didalam menjalankan program dukungan keluarga yang negatif juga dapat menjadi hambatan dalam melaksanakan program pemulihan pasien dan tidak teratur dalam kontrol setelah rawat inap selesai juga salah satu hambatan bagi program pemulihan maka himbauan dari kami untuk keluarga pasien selalu disarankan selalu memotivasi keluarganya dan 
rajinlah kontrol serta minum obat sesuai saran dokter". (Hasil wawancara yang diperoleh dari Ibu dr. Purnama Sari Dalimunthe tanggal 26 Juli 2019).

Dari hasil penelitian yang telah dilakukan dari 4 narasumber eks orang dengan gangguan jiwa, 3 narasumber team medis dan 1 narasumber pimpinan Rumah Sakit Jiwa bahwa peranan Rumah Sakit Jiwa Mahoni dalam menjalankan program penyembuhan berjalan dengan baik karena eks orang dengan gangguan yang keluar setelah melakukan perawatan memiliki kondisi yang stabil dan membaik. Disamping terapi obat-obatan yang dikonsumsi setiap hari dan melakukan kontrol sesuai anjuran dokter. Eks Orang dengan gangguan jiwa sudah dapat kembali menjalankan aktifitasnya bekerja dan belajar sebagai mahasiwa.

Dengan adanya program penyembuhan di Rumah Sakit Jiwa Mahoni dapat dilihat eks orang dengan gangguan jiwa Bapak Hamonangan Sagala, Bapak Armansyah, Bapak Edi surya, Bapak Alni Rafiqi Sagala dinyatakan sembuh oleh dokter dan mendapat ijin untuk keluar dari Rumah Sakit Jiwa. Komunikasi yang dinilai sudah mulai membaik dan nyambung kemudian dapat diarahkan serta dinasehati dan dimotivasi. Eks orang dengan gangguan jiwa tersebut juga sudah bisa tidur dan melakukan kebiasaan dan kegiatan yang bersifat positif.

Maka dapat disimpulkan bahwa peranan Rumah Sakit Jiwa dalam mengembalikan keberfungsian sosial eks orang dengan gangguan jiwa dilihat dari aspek program penyembuhan sudah mulai berhasil sebab pada saat saya melakukan wawancara kepada 4 eks orang dengan gangguan jiwa rata-rata mereka sudah kembali ke keluarganya dalam kondisi stabil serta yang lebih membahagiakan adalah keberfungsian sosial berfungsi setelah menjalani peogram penyembuhan di Rumah Skait Jiwa Mahoni di informasikan dari mereka pada wawancara mereka juga sudah mulai bekerja kembali untuk mencukupi kebutuhan hidup.

\section{Aspek Program Pemulihan}

Proses pemulihan orang dengan gangguan jiwa di rumah sakit jiwa mahoni dilaksanakan oleh team medis, pada saat itu ada 3 team medis yakni perawat yang sedang bertugas merawat pasien. Pada setiap harinya tugas dari perawat sendiri dibagi menjadi 3 shift dengan 1 kali shift yang bertugas ada 3 perawat. Ibu Sumastri merupakan salah satu perawat senior yang bekerja di Rumahh Sakit Jiwa Mahoni. Beliau sudah bekerja selama 10 tahun sebagai perawat, berusia 46 tahun. 
Ekasari, Yuli. Agus, Efendi. Peranan Rumah Sakit Jiwa Mahoni Dalam Mengembalikan Keberfungsian Sosial Eks Orang Dengan Gangguan Jiwa

“Orang stress harus diarahkan tentang kebersihan, kebersihan cerminan dari sebagian dari iman. Dengan dia beriman stress nya Insya Allah berkurang. Orarng stress juga harus rajin minum obat tepat waktu supaya jangan kambuh serta diberikan waktu istirahat tiduran pada waktunya". (Hasil wawancara yang diperoleh dari Ibu perawat Sumastri tanggal 26 Juli 2019).

Berdasarkan hasil wawancara dengan narasumber mengenai proses penyembuhan yakni dengan adanya dukungan dari keluarga pasien. Keluarga memang hendaknya memberikan semangat serta motivasi kepada pasien agar pasien dapat segera sembuh.

"Biasanya proses penyembuhan dan pemulihan pasien selain dari resep obatobatan dan suntikan dari dokter, dukungan keluarga juga ikut berperan dalam proses penyembuhan dan pemulihan pasien". (Hasil wawancara yang diperoleh dari Ibu perawat Mastiur tanggal 26 Juli 2019).

Proses penyembuhan pasien ternyata juga bisa melalui jadwal dan kegiatan positif yang dilakukan selama dirawat di Rumah Sakit Jiwa mahoni, diberitahukan saat wawancara dengan dengan perawat yang bernama Agus Sulaiman yang berusia 23 tahun dan baru bekerja di Rumah Sakit Jiwa Mahoni sebagai perawat selama 1 bulan.

“Proses penyembuhan dilakukan dengan terapi obat, selain itu pasien juga harus melakukan jadwal khusus misalnya olahraga di hari sabtu pagi senam bersama dan mengikuti kegiatan keagamaan sesuai agama masing-masing atau juga ada kegiatan yang positif seperti melukis mewarnai dan lain sebagainya". (Hasil wawancara yang diperoleh dari perawat Agus Sulaiman tanggal 26 Juli 2019).

Berdasarkan hasil penelitian dari wawancara ada proses pemulihan di Rumah Sakit Jiwa Mahoni yang terdiri dari 3 narasumber team medis perawat ibu Mastiur, Ibu Sumastri, dan Bapak Agus Sulaiman dinilai berhasil sebab kebanyakan eks orang dengan gangguan jiwa seluruhnya selalu rajin menjalani terapi obat-obatan setelah diizinkan dokter pulang kerumah serta menjalani kontrol kembali atau rawat jalan sesuai anjuran dokter.

Proses penyembuhan yang dilakukan di Rumah Sakit Jiwa Mahoni selain dengan memberitahu keluarga untuk selalu rajin mengkonsumsi obat-obatan juga dibarengi dengan mmeberikan dukungan kepada mereka agar dapat segera sembuh antara lain 
seperti memotivasi pasien untuk melakukan kegiatan positif, mengajak pasien untuk mengerjakan urusan spiritualnya, mengajarkan pasien untuk dapat mengukur emosionalnya secara mandiri, harus taat pada peraturan serta selalu menjaga kebersihan.

Dibuktikan dari wawancara terhadap 3 narasumber team medis perawat, mereka menjalankan proses penyembuhan dengan baik dan para eks orang dengan gangguan jiwa yang sudah selesai rawat inap seluruhnya rajin mengikuti rawat jalan.

\section{Aspek Faktor Biologis}

Faktor Biologis. Proses munculnya gangguan jiwa dipengaruhi oleh banyak faktor salah satunya adalah faktor biologis. Faktor genetik ada hubungannya dengan gangguan mental seseorang. Apabila orang tua menderita gangguan mental, maka 35-68\% anaknya menderita juga gangguan mental.

Hasil wawancara dengan eks orang dengan gangguan jiwa ada 4 narasumber mengatakan bahwa 3 diantaranya penyebab awalnya adalah karena penyalahgunaan narkoba yang memiliki dampak pada kejiwaan pasien. Bapak Hamonangan Sagala, Bapak Armansyah, Bapak Edi Surya memiliki beragam penyakit kejiwaan hanya karena mengkonsumsi narkoba. Apa faktor penyebab saudara hingga dirawat di Rumah Sakit Jiwa Mahoni?

"Aku dirawat di mahoni karena narkoba lah jadinya emosional meledakledak sama marah-marah hebat". (hasil wawancara ketiga narasumber Bapak Hamonangan Sagala, Bapak Armansyah, Bapak Edi Surya tanggal 26 Juli 2019)

Berdasarkan dari hasil penelitian terhadap 4 narasumber eks orang dengan gangguan jiwa yakni Bapak Hamonangan Sagala, Bapak Armansyah, Bapak Alni Rafiqi Sagala, dan Bapak Edi Surya bukanlah berasal dari faktor biologis. Faktor biologis biasanya keturunan atau memiliki hubungan darah melalui orang tuanya. Dilihat dari hasil wawancara dengan 4 narasumber eks orang dengan gangguan jiwa bahwasannya faktor penyebab timbulnya penyakit gangguan jiwa yang berasal dari faktor biologis masih kurang sebab hanya yang memiliki keturunan sakit jiwa lah yang kemungkinan kecil dapat menurun ke anak-anaknya. 
Ekasari, Yuli. Agus, Efendi. Peranan Rumah Sakit Jiwa Mahoni Dalam Mengembalikan Keberfungsian Sosial Eks Orang Dengan Gangguan Jiwa

\section{Aspek Faktor Psikologis}

Selain faktor biologis, faktor psikologis seseorang juga ada hubungannya dengan gangguan jiwa dan mental dimana kondisi orang dengan dengan gangguan jiwa itu dengan peristiwa hidupnya. Setiap penderita yang mengalami gangguan jiwa memperlihatkan satu tidak kuatnya hubungan personal dengan lingkungan sekitar. Gejala yang diperlihatkan penderita merupakan perwujudan dari pengalaman masa lampaunya.

Seperti eks orang dengan gangguan jiwa yang pernah dirawat di Rumah Sakit Jiwa Mahoni yakni Alni Rafiqi Sagala.

"Aku merasa seperti di ganggu oleh mahkluk asing jin jadi ada timbul semacam ilusi dipikiran aku juga kadang menjadi berhalusinasi mengerikan sampai kadang aku berteriak teriak". (Hasil wawancara dengan mahasiswa Alni rafiqi Sagala 26 Juli 2019).

Dari hasil penelitian melalui wawancara maka faktor psikologis dinilai menjadi penyebab seseorang menderita gangguan jiwa. Rumah Sakit Jiwa menambahkan kegiatan keagamaan, agama dapat mengembalikan tekanan kehidupan kea rah normal dengan menjadi benteng pertahanan terhadap tekanan kehidupan sehingga jauh dari stress. Disamping itu juga kegiatan lain yang mendukung berkembangnya interatif terhadap lingkungan sekitarnya untuk menghindari kesendirian bagi penderita gangguan jiwa yang sedang melakukan pemulihan.

\section{Aspek Faktor Sosiolultural}

Faktor sosialkultural menjadi salah satu faktor penyebab seseorang mengalami gangguan kejiwaan. Konflik konflik sosial dan kultural mempengaruhi diri manusia. pikiran manusia itu terdapat suatu energi yang muncul dan dibentuk oleh kondisi yang mengarah pada hal-hal positif seperti cinta kasih, keyakinan, ketenangan dan kesadaran juga hal-hal yang negatif dibangun oleh kondisi pikiran yang selalu muncul rasa iri, dengki, serakah, sombong, khawatir, ragu-ragu, egois, putus asa dan lainnya.

Kita mengetahui bahwa dalam hidup manusia itu selalu terdapat konflik, ada kekalutan jiwa yang menampilkan diri dalam tingkah laku dipenuhi oleh rasa panik dan gambaran-gambaran yang khayali kemudian timbul meledak-ledak yang membahayakan orang lain juga dirinya sendiri. Dari hasil wawancara dengan narasumber eks orang dengan gangguan jiwa karena efek narkoba yang luar biasa menjadikan diri mereka 
menjadi diluar kendali. Tiga narasumber ini adalah Bapak hanonangan sagala, Bapak Edi Surya, Bapak Armansyah menderita gangguan jiwa berawal karena pemakaian narkoba.

"Keluargaku nggak begitu tahan dengan tingkah emosionalku jadi dibawa berobat ke mahoni dirawat lah aku selama ini, dan Alhamdulillah keluarga masih sayang sama bapak. Menyesal lah karena kalau udah emosi bapak bahaya kali dulu itu. Ini bapak dokter pesan rajin minum obat biar stabil jangan emosiemosi lagi bapak. Ini bapak udah nggak mau dekat lagi dengan lingkungan yang menjerumuskan".. (Hasil wawancara dengan Bapak hamonangan sagala tanggal 26 Juli 2019).

“Pemake narkoba dek jadi ya gitulah kalau ngak dapat bingung mau juga jadinya emosional ujungnya ngamuk-ngamuk lempar barang campak sana sini”. (Hasil wawancara dengan Bapak Armansyah tanggal 26 Juli 2019).

"Aku dulu kalau kumat marah-marah sambil banting-banting barang yang ada dirumah, jadi berobat lah aku di mahoni semuanya diobati, sekarang aku udah gak mau lagi sama yang namanya narkoba. Rugi kali kurasa kadang”. ( Hasil wawancara dengan Bapak Edi surya tanggal 26 Juli 2019).

Secara keseluruhan dari hasil penelitian bahwa faktor sosialkultural dari 4 narasumber eks orang dengan gangguan jiwa yang pernah dirawat di Rumah Sakit Jiwa Mahoni dapat di atasi dengan baik. Team medis Rumah Sakit Jiwa Mahoni selain melakukan terapi obat-obatan juga memperbaiki hubungan eks orang dengan gangguan jiwa dengan pola perilakunya. Gangguan mental dikarenakan faktor sosialkultural dapat dihindari dengan selalu menjaga kebersihan, menghindari konflik batin yang serius dan konflik dengan lingkungannya.

Menurut Wiramihardja (2004), secara ilmiah yang disebut gangguan kejiwaan sangat bervariasi dan pada dasarnya gangguan kejiwaan meliputi tiga pengertian utama, yaitu: a). Menyimpang dari standar kultural atau sosial. Ullman dan Krasner berpendapat, seperti dikemukakan juga oleh Coelman dkk, bahwa tidak ada tingkah laku abnormal selama masyarakat menerimanya, hal ini dapat diartikan bahwa tidak ada masyarakat yang sakit selama ukuran sakit dan sehat di dalam masyarakat masih bervariasi. b). Ketidakmampuan menyesuaikan diri. Pandangan ini menyatakan bahwa perilaku abnormal adalah perilaku yang maladaptive (tidak sesuai/tidak adanya kesesuaian) ketika individu berada dalam kondisi atau situasi yang menuntutnnya melakukan tindakan menyesuaikan diri dengan baik. c). 
Ekasari, Yuli. Agus, Efendi. Peranan Rumah Sakit Jiwa Mahoni Dalam Mengembalikan Keberfungsian Sosial Eks Orang Dengan Gangguan Jiwa

Menyimpang secara statistik. Norma-norma numerik yang didasarkan pada prosedur statistik, dapat dijadikan landasan bagi pengelompokan perilaku.Dalam kriteria ini yang paling mudah dipahami adalah menyangkut fungsi mental yang disebut kecerdasan.

Taraf kecerdasan antara 90 dan 110 adalah kecerdasan orang pada umumnya. Kurang dari 90 termasuk rendah dan di atas 110 adalah termasuk memiliki kecerdasan tinggi. Orang yang taraf kecerdasannya 90 sampai 110 adalah orang yang kecerdasannya tergolong normal. Dikatakan abnormal atau subnormal jika kecerdasannya di bawah 90. Dapat juga dinamakan abnormal apabila di atas 110, tetapi bukan subnormal melainkan diatas normal atau above averege bahkan selanjutnya superior.

\section{SIMPULAN}

Setelah peneliti melakukan penelitian tentang Peranan Rumah Sakit Jiwa Mahoni Dalam Mengembalikan Keberfungsian Sosial Eks Orang Dengan Gangguan Jiwa Didalam Keluarga, maka dapat disimpulkan yaitu :

Pertama. Peranan Rumah Sakit Jiwa Mahoni Dalam Mengembalikan Keberfungsian Sosial Eks Orang Dengan Gangguan Jiwa Didalam Keluarga dinilai sangat membantu dikarekan adanya program penyembuhan dan proses pemulihan bagi penderita gangguan jiwa yang melakukan pengobatan dengan rawat inap. Disamping itu juga pasien yang sudah diijinkan oleh dokter untuk pulang juga tetap melakukan pengobatan dengan rawat jalan kontrol minimal 2 minggu sekali serta tetap melakukan terapi obatobatan untuk menjaga kondisi eks orang gangguan jiwa yang sudah keluar bisa tetap dalam kondisi stabil.

Kedua. Orang dengan gangguan jiwa diakibatkan oleh beberapa faktor diantaranya faktor biologis, faktor psikologis, dan faktor sosialkultural. Perbedaan dalam penanganan dikarenakan faktor membutuhkan usaha yang lebih rajin dan giat lagi bagi para team medis dalam memberikan pengobatan yang maksimal kepada pasien orang dengan gangguan jiwa.

Ketiga. Rumah Sakit Jiwa Mahoni dinilai berhasil dalam mengembalikan keberfungsian sosial eks orang gangguan jiwa dikarenakan mereka pada saat kembali ke rumah/ keluarga sudah dapat kembali melakukan kegiatan / aktifitas layaknya orang normal. Komunikasi yang sudah semakin membaik kondisi mental dan jiwa kembali normal, teratur dan disiplin dalam mengkonsumsi obat-obatan untuk menghindari kumat. 


\section{DAFTAR PUSTAKA}

Huda, M. (2009). Pekerjaan Sosial dan Kesejahteraan Sosial (Sebuah Pengantar). Yogyakarta: Pustaka Pelajar.

Moleong, L. (2006). Metodologi Penelitian Kualitatif. Jakarta: PT. Remaja Rosdakarya.

Rahman, A. A. (2013). Psikologi Sosial. Jakarta: Penerbit RajaGrafindo Persada.

Rukminto, A. I. (2013). Kesejahteraan Sosial. Jakarta: PT RajaGrafindo Persada.

Suliswati. (2005). Konsep Dasar Keperawatan Kesehatan Jiwa. Jakarta: EGC.

Wiramihardja, S. A. (2004). Pengantar Psikologi Klinis. Bandung: Refika Aditama.

Yustinus, S. (2006). Kesehatan Mental I. Yogyakarta: Kanisius. 